\title{
Bending and Free Vibration Analysis of Isotropic Plate Using Refined Plate Theory
}

\author{
I.I. Sayyad, S.B. Chikalthankar and V.M. Nandedkar
}

\begin{abstract}
In this paper, Trigonometric shear deformation theory is applied for bending and free vibration analysis of thick plate. In this theory in plane displacement field uses sinusoidal function in terms of thickness coordinate. It accounts for realistic variation of the transverse shear stress through the thickness and satisfies the shear stress free surface conditions at the top and bottom surfaces of the plate. The theory obviates the need of shear correction factor like other higher order or equivalent shear deformation theories. Simply supported thick isotropic plate is considered for detail numerical study. Navier's solution technique is employed for the analytical solution. The results are obtained for displacements, stresses and natural bending mode frequencies and compared with those of other refined theories and exact solution from theory of elasticity.
\end{abstract}

Keywords--- Natural Frequencies, Shear Correction Factor, Shear Deformation, Transverse Shear Stress

\section{INTRODUCTION}

I $\mathrm{n}$ classical plate theory, it is assumed that line which is normal to the neutral surface before deformation remain straight and normal to the neutral surface after deformation. This assumption results in under-estimation of deflection and over-estimation of natural frequencies and buckling loads. The errors in deflection, stresses, natural frequencies and bulking loads are even higher for plates made out of advanced composites like graphite epoxy; boron epoxy etc,. in the early days [1-7] the classical plate theory was extended for the analysis of the composite structures.

Later the importance of shear effect in plate bending was realized and the higher order theories were developed which take transverse stresses and strains into account. Higher order theories aim at improving the accuracy by incorporating transverse strains/stresses in the formulation.

For higher order theories, primarily two types of approaches are available. In the first one the stresses are treated as primary variable and the displacements are found. In the second approach displacements are treated as primary variables and the stresses are found.

I.I. Sayyad, P.G., Student, Department of Mechanical Engineering, Government College of Engineering, Aurangabad, India, E-mail: sayyadimrani@gmail.com

S.B. Chikalthankar, Associate Professor, Department of Mechanical Engineering, Government College of Engineering, Aurangabad, India.

V.M. Nandedkar, Professor, Department of Production Engineering, SGGS Institute of Engineering and Technology, Nanded, India
First Order Shear Deformation Theory (FSDT) [8-9] is the starting point in the development of plate theories in which transverse shear effects were included. In this theory, constant shear strain is assumed across the thickness and it predicts average shear stress. It also requires a shear correction coefficient, accurate evaluation of which is problem specific [10]. This theory has been widely used for static, free vibration and transient analysis because of its simplicity and good global predictions.

The plate theories are further refined by assuming parabolic (higher order parabolas) shear strain variation across the thickness and these are called as Higher order Shear Deformation Theories (HSDT). It is very well known that HSDT gives more accurate results and very close to three dimensional (3-D) elasticity solution for static loading conditions and free vibrations. Higher order theories are based on realistic displacement models, which give rise to nonlinear distribution of in-plane, normal and transverse shear strains. The higher order theories are quite involved and are more complicated as compared to the CPT and FSDT. It is very important to develop a higher order theory, which is simple and easy to use. Good review on plate theories is given in references [11-17]

In the present work, emphasis has been laid on specific development of Trigonometric Shear Deformation Theory (TSDT) for plate analysis. And the effectiveness of this theory is shown by applying it to static and dynamic problems of isotropic plates. The displacement models contain trigonometric terms in addition to classical plate theory terms. This displacement models is different from the generalized model of LO and Christensen [18-19] which contains only polynomial terms. Use of trigonometric functions to describe the plate behavior in thickness direction was first proposed by Stein [20-21] and was used for laminated beam and post buckling analysis of plates. Reddy and Phan had carried out stability and vibration of isotropic, orthotropic and laminated plates according to higher order shear deformation theory [22]. However, the present TSDT model differs from that of Stein. In Stein's the top and bottom shear stress conditions are not satisfied.

Higher order theories, which consider plate properties in a smeared manner, fail to interlaminar stresses at interfaces accurately. Transverse stresses are very important in the composite analysis since interlaminar stresses are primarily responsible for delamination. This failure is overcome by developing the theories, which considers the behavior of individual layer in the analysis, and these types of theories are called as layer-by-layer theories. 
The extensive use of advanced composite materials in the various high performance structures led to the development of refined theories for analysis of such structures in order to address the correct structural behavior. The objective of this paper is to present a trigonometric shear deformation theory for isotropic thick plates. It includes the effect of transverse shear. Results obtained for uniformly distributed loading case and are compared with those of refined theories like Ghugal and Sayyad[23], Krishnamurthy[24], Reddy[25], Mindlin[9], Kirchhoff[3] and exact elasticity theory [26] available in the literature.

\section{THEORETICAL FORMULATION}

\section{A. The Plate under Consideration:}

The plate under consideration occupies in $O-x-y-z$ Cartesian coordinate system the region:

$$
0 \leq x \leq a ; \quad 0 \leq y \leq b ; \quad-h / 2 \leq z \leq h / 2
$$

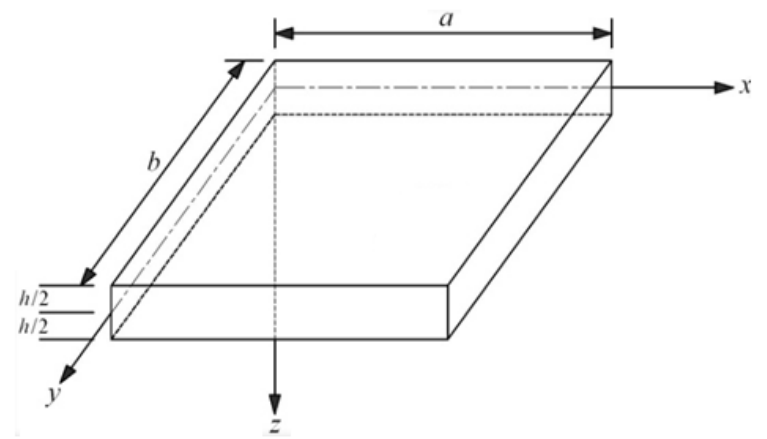

Figure 1: Geometry of Thick plate

Where $x, y, z$ are Cartesian coordinates, $a$ and $b$ are the edge lengths in the $x$ and $y$ directions respectively and $h$ is the thickness of the plate. The plate is made up of homogeneous, linearly elastic isotropic material with the principal material axes parallel to the $x$ and $y$ axes in the plane of plate. The plate material obeys generalized Hooke's law. For isotropic plate the material properties are $\mathrm{E}_{1}=\mathrm{E}_{2}=\mathrm{E}=200 \mathrm{GPa}, \mathrm{G}_{12}=\mathrm{G}_{23}=\mathrm{G}_{31}=\mathrm{G}$, $\mu_{12}=\mu_{21}=\mu=0.3$

- Assumptions made in the Theoretical Formulation:

1. The displacements are small and, therefore, strains involved are infinitesimal.

2. The in plane displacement $u$ in $x$ direction as well as displacement $v$ in $y$ direction each consists of three parts:

a) Displacement component analogous to the displacement in classical plate theory of bending.

b) Displacement component due to shear deformation, which is assumed to be sinusoidal in nature with respect to thickness coordinate, such that the maximum shear stress occurs at neutral axis.

3 . The transverse displacement $w$ in $z$ direction is assumed to be a function of $x$ and $y$ coordinates only.

4. The plate can be subjected to transverse as well as in plane loads.

\section{B. The Displacement Field}

Based on the before mentioned assumptions, the displacement field of the
Present Refined Plate Theory (RPT) can be expressed as follows:

$$
\begin{aligned}
& u=-z \frac{\partial w}{\partial x}+\frac{h}{\pi} \sin \frac{\pi z}{h} \phi(x, y, t) \\
& v=-z \frac{\partial w}{\partial y}+\frac{h}{\pi} \sin \frac{\pi z}{h} \psi(x, y, t) \\
& w=w(x, y, t)
\end{aligned}
$$

Here $u$ and $v$ are the in plane displacement components in the $x$ and $y$ directions respectively and $w$ is the transverse displacement in the $z$ direction. The trigonometric function in terms of thickness coordinate in both the displacements $u$ and $v$ is associated with the transverse shear stress distribution through the thickness of plate and the functions $\phi(x, y, t)$ and $\psi(x, y, t)$ are the unknown functions associated with the shear slopes.

\section{Strain-Displacement Relationships}

Normal and shear strains are obtained within the framework of linear theory of elasticity using the displacement field given by (2). These relationships are given as follows:

Normal Strain:

$$
\begin{aligned}
& \varepsilon_{x}=\frac{\partial u}{\partial x}=-z \frac{\partial^{2} w}{\partial^{2} x}+\frac{h}{\pi} \sin \frac{\pi z}{h} \frac{\partial \phi}{\partial x} \\
& \varepsilon_{y}=\frac{\partial v}{\partial y}=-z \frac{\partial^{2} w}{\partial^{2} y}+\frac{h}{\pi} \sin \frac{\pi z}{h} \frac{\partial \psi}{\partial y} \\
& \varepsilon_{z}=\frac{\partial w}{\partial z}=0
\end{aligned}
$$

Shear Strains:

$$
\begin{aligned}
& \gamma_{x y}=\frac{\partial u}{\partial y}+\frac{\partial v}{\partial x}=-2 \frac{\partial^{2} w}{\partial x \partial y}+\frac{h}{\pi} \sin \frac{\pi z}{h}\left(\frac{\partial \phi}{\partial y}+\frac{\partial \psi}{\partial x}\right) \\
& \gamma_{z x}=\frac{\partial u}{\partial z}+\frac{\partial w}{\partial x}=\cos \frac{\pi z}{h} \phi \\
& \gamma_{y z}=\frac{\partial v}{\partial z}+\frac{\partial w}{\partial y}=\cos \frac{\pi z}{h} \psi
\end{aligned}
$$

\section{Stress-Strain Relationships:}

For a linearly elastic isotropic material, stresses $\tau_{x y}, \sigma_{\mathrm{x}}$ and $\sigma_{\mathrm{y}}$ are related to strains $\gamma_{x y}, \varepsilon_{x}$ and $\varepsilon_{y}$ shear stresses are related to shear strains by the following constitutive relations:

$\left\{\begin{array}{c}\sigma_{x} \\ \sigma_{y} \\ \tau_{x y}\end{array}\right\}=\left[\begin{array}{ccc}Q_{11} & Q_{12} & 0 \\ Q_{12} & Q_{22} & 0 \\ 0 & 0 & Q_{66}\end{array}\right]\left\{\begin{array}{c}\varepsilon_{x} \\ \varepsilon_{y} \\ \gamma_{x y}\end{array}\right\}$ and

$\left\{\begin{array}{l}\tau_{y z} \\ \tau_{z x}\end{array}\right\}=\left[\begin{array}{cc}Q_{44} & 0 \\ 0 & Q_{55}\end{array}\right]\left\{\begin{array}{l}\gamma_{y z} \\ \gamma_{z x}\end{array}\right\}$ 
where $\sigma_{x}, \sigma_{y}$ and $\tau_{x y}$ are the in plane stresses and $\tau_{y z}, \tau_{z x}$ are the transverse shear stresses. They $\left(\varepsilon_{x,} \varepsilon_{y,}\right)$ are normal strain component, $\left(\gamma_{x y}, \gamma_{y z}, \gamma_{z x}\right)$ are the shear strain components and $Q_{i j}$ are the stiffness coefficients [27].

\section{Governing Equations and Boundary Conditions}

Using the expressions for strains and stresses through (5) and using the principle of virtual work, variationally consistent governing differential equations and boundary conditions for the plate under consideration can be obtained.

The principle of virtual work when applied to the plate leads to:

$$
\begin{aligned}
& \int_{z=-h / 2}^{z=h / 2} \int_{y=0}^{y=b} \int_{x=0}^{x=a}\left[\begin{array}{l}
\sigma_{x} \delta \varepsilon_{x}+\sigma_{y} \delta \varepsilon_{y}+\sigma_{z} \delta \varepsilon_{z} \\
+\tau_{y z} \delta \gamma_{y z}+\tau_{z x} \delta \gamma_{z x}+\tau_{x y} \delta \gamma_{x y}
\end{array}\right] d x d y d z \\
& -\int_{y=0}^{y=b} \int_{x=0}^{x=a} q(x, y) \delta w d x d y \\
& +\rho \int_{z=-h / 2}^{z=h / 2} \int_{y=0}^{y=b} \int_{x=0}^{x=a}\left[\frac{\partial^{2} u}{\partial t^{2}} \delta u+\frac{\partial^{2} v}{\partial t^{2}} \delta v+\frac{\partial^{2} w}{\partial t^{2}} \delta w\right] d x d y d z \\
& -\int_{y=0}^{y=b} \int_{x=0}^{x=a}\left(\bar{N}_{x} \frac{\partial^{2} w}{\partial x^{2}} \delta w+\bar{N}_{y} \frac{\partial^{2} w}{\partial y^{2}} \delta w\right) d x d y=0
\end{aligned}
$$

Where symbol $\delta$ denotes the variation operator.

Integrating (6) by parts and collecting coefficients of $\delta w, \delta \phi$ and $\delta \psi$ following governing differential equations and the associated boundary conditions are obtained.

The governing differential equations obtained are as follows:

$$
\begin{aligned}
& \left\{\begin{array}{l}
Q_{11} A \frac{\partial^{4} w}{\partial x^{4}}+\left(2 Q_{12} A+4 Q_{66} A\right) \frac{\partial^{4} w}{\partial x^{2} \partial y^{2}}+Q_{22} A \frac{\partial^{4} w}{\partial y^{4}} \\
-Q_{11} B \frac{\partial^{3} \phi}{\partial x^{3}}-\left(Q_{12} B+2 Q_{66} B\right) \frac{\partial^{3} \phi}{\partial x \partial y^{2}} \\
-Q_{22} B \frac{\partial^{3} \psi}{\partial y^{3}}-\left(Q_{12} B+2 Q_{66} B\right) \frac{\partial^{3} \psi}{\partial x^{2} \partial y}-\rho A \frac{\partial^{4} w}{\partial x^{2} \partial t^{2}} \\
-\rho A \frac{\partial^{4} w}{\partial y^{2} \partial t^{2}}+\rho B \frac{\partial^{3} \phi}{\partial x \partial t^{2}}+\rho B \frac{\partial^{3} \psi}{\partial Y \partial t^{2}}+\rho H \frac{\partial^{2} w}{\partial t^{2}}
\end{array}\right\}=q \\
& Q_{11} B \frac{\partial^{3} w}{\partial x^{3}}+\left(Q_{12} B+2 Q_{66} B\right) \frac{\partial^{3} w}{\partial x \partial y^{2}}-Q_{11} C \frac{\partial^{2} \phi}{\partial x^{2}} \\
& -Q_{66} C \frac{\partial^{2} \phi}{\partial y^{2}}-\left(Q_{12} C+Q_{66} C\right) \frac{\partial^{2} \psi}{\partial x \partial y}+Q_{55} D \phi \\
& -\rho B \frac{\partial^{3} w}{\partial x \partial t^{2}}+\rho C \frac{\partial^{2} \phi}{\partial t^{2}} \quad=0 \\
& {\left[\begin{array}{l}
Q_{22} B \frac{\partial^{3} w}{\partial y^{3}}+\left(Q_{12} B+2 Q_{66} B\right) \frac{\partial^{3} w}{\partial x^{2} \partial y} \\
-\left(Q_{12} C+Q_{66} C\right) \frac{\partial^{2} \phi}{\partial x \partial y}-Q_{66} C \frac{\partial^{2} \psi}{\partial x^{2}}-Q_{22} C \frac{\partial^{2} \psi}{\partial y^{2}}
\end{array}\right]=0} \\
& +Q_{44} D \psi-\rho B \frac{\partial^{3} w}{\partial y \partial t^{2}}+\rho C \frac{\partial^{2} \psi}{\partial t^{2}}
\end{aligned}
$$

The associated consistent boundary conditions obtained are as below:

Along the edge $x=0$ and $x=a$

$Q_{11} A \frac{\partial^{2} w}{\partial x^{2}}-Q_{11} B \frac{\partial \phi}{\partial x}+Q_{12} A \frac{\partial^{3} \omega}{\partial y^{2}}-Q_{12} B \frac{\partial \psi}{\partial y}=0$

or $\frac{\partial w}{\partial x}$ is prescribed.

$-Q_{11} A \frac{\partial^{3} w}{\partial x^{3}}+Q_{11} B \frac{\partial^{2} \phi}{\partial x^{2}}-Q_{12} A \frac{\partial^{3} w}{\partial x \partial y^{2}}+Q_{12} B \frac{\partial^{2} \psi}{\partial x \partial y}$

$-4 Q_{66} A \frac{\partial^{3} w}{\partial x \partial y^{2}}-4 Q_{66} A \frac{\partial^{3} w}{\partial x^{2} \partial y}+2 Q_{66} B \frac{\partial^{2} \phi}{\partial y^{2}}$

$+2 Q_{66} B \frac{\partial^{2} \phi}{\partial x \partial y}+2 Q_{66} B \frac{\partial^{2} \psi}{\partial x \partial y}+\rho A \frac{\partial^{3} w}{\partial x \partial t^{2}}-\rho B \frac{\partial^{2} \phi}{\partial t^{2}}$

$=0$ or $\mathrm{W}$ is prescribed.

$-Q_{11} B \frac{\partial^{2} w}{\partial x^{2}}+Q_{11} C \frac{\partial \phi}{\partial x}-Q_{12} B \frac{\partial^{2} w}{\partial y^{2}}+Q_{12} C \frac{\partial \psi}{\partial y}=0$

or $\phi$ is prescribed.

$-2 Q_{66} B \frac{\partial^{2} w}{\partial x \partial y}+Q_{66} C \frac{\partial \phi}{\partial y}+Q_{66} C \frac{\partial \psi}{\partial y}=0$

or $\psi$ is prescribed.

Along the edge $y=0$ and $y=b$ :

$$
\begin{aligned}
& Q_{12} A \frac{\partial^{2} w}{\partial x^{2}}-Q_{12} B \frac{\partial \phi}{\partial y}+Q_{22} A \frac{\partial^{2} \omega}{\partial y^{2}}-Q_{22} B \frac{\partial \psi}{\partial y}=0 \\
& \text { or } \frac{\partial w}{\partial y} \text { is prescribed. }
\end{aligned}
$$

$$
\begin{gathered}
-Q_{12} A \frac{\partial^{3} w}{\partial x^{2} \partial y}+Q_{12} B \frac{\partial^{2} \phi}{\partial x \partial y}-Q_{22} A \frac{\partial^{3} w}{\partial y^{3}}+Q_{22} B \frac{\partial^{2} \psi}{\partial y^{2}} \\
-4 Q_{66} A \frac{\partial^{3} w}{\partial x^{2} \partial y}+2 Q_{66} B \frac{\partial^{2} \phi}{\partial x \partial y}+2 Q_{66} B \frac{\partial^{2} \psi}{\partial x^{2}} \\
+\rho A \frac{\partial^{3} w}{\partial y \partial t^{2}}-\rho A \frac{\partial^{2} \psi}{\partial t^{2}}=0 \text { or } \mathrm{w} \text { is prescribed. } \\
-2 Q_{66} B \frac{\partial^{2} w}{\partial x \partial y}+Q_{66} C \frac{\partial \phi}{\partial y}+Q_{66} C \frac{\partial \psi}{\partial x}=0
\end{gathered}
$$

or $\phi$ is prescribed.

$$
-Q_{12} B \frac{\partial^{3} w}{\partial x^{2}}+Q_{12} C \frac{\partial \phi}{\partial x}-Q_{22} B \frac{\partial^{2} \omega}{\partial y^{2}}+Q_{22} C \frac{\partial \psi}{\partial y}=0
$$

or $\psi$ is prescribed.

Thus, the variationally consistent governing differential equations and boundary conditions are obtained. The values of integration constants A,B,C and D are mentioned below.

$$
\begin{aligned}
& A=\int_{-h / 2}^{h / 2} z^{2} d z=\frac{h^{3}}{12}, \quad \mathrm{C}=\int_{-h / 2}^{h / 2} f^{2}(z) d z=\frac{h^{3}}{2 \pi^{2}} \\
& B=\int_{-h / 2}^{h / 2} z \mathrm{f}(\mathrm{z}) \mathrm{dz}=2\left(\frac{h}{\pi}\right)^{3}, \mathrm{D}=\int_{-h / 2}^{h / 2}\left[\frac{d f(z)}{d z}\right]^{2} d z=\frac{h}{2}
\end{aligned}
$$


The flexural behavior of the plate is described by the solution satisfying these equations and the associated boundary conditions at each edge and corner of the plate.

\section{ILLUSTRATIVE EXAMPLES}

Example 1: A simply supported isotropic rectangular plate subjected to uniformly distributed load. The rectangular plate occupying the region given by the (1) is considered, the plate is subjected to uniformly distributed transverse load, $\mathrm{q}(\mathrm{x}, \mathrm{y})$ on surface $\mathrm{z}=-\mathrm{h} / 2$ acting in the downward $\mathrm{z}$-direction as given below:

$$
q(x, y)=\sum_{m=1}^{\infty} \sum_{n=1}^{\infty} q_{m n} \sin \left(\frac{m \pi x}{a}\right) \sin \left(\frac{n \pi y}{b}\right)
$$

Where, $q_{m n}$ are the coefficients of Fourier expansion of load, which are given by,

$$
\mathrm{q}_{\mathrm{mn}}=\frac{16 \mathrm{q}_{0}}{\mathrm{mn} \pi^{2}} \text { for } \mathrm{m}=1,3,5, \ldots . ., \text { and } \mathrm{n}=1,3,5, \ldots . .
$$

$\mathrm{q}_{\mathrm{mn}}=0$ for $\mathrm{m}=2,4,6, \ldots .$. , and $\mathrm{n}=2,4,6, \ldots .$.

The plate material are considered as $E=210 \mathrm{GPa}$ and $\mu=0.3$, where $E$ is the Young's modulus and $\mu$ is the Poisson's ratio. The governing differential equations and the associated boundary conditions for static flexure of rectangular plate under consideration can be obtained directly from (7) through (9). The following are the boundary conditions of the simply supported isotropic plate on the edges $\mathrm{x}=0$ and $\mathrm{x}=\mathrm{a}$.

\section{Navier Solution}

The following is the solution form for $w(x, y), \phi(x, y)$, and $\psi(x, y)$ satisfying the boundary conditions given by the (8) and (9) perfectly for a plate with all the edges simply supported:

$$
\begin{aligned}
& w(x, y)=\sum_{m=1}^{\infty} \sum_{n=1}^{\infty} w_{m n} \sin \frac{m \pi x}{a} \sin \frac{n \pi y}{b} \\
& \phi(x, y)=\sum_{m=1}^{\infty} \sum_{n=1}^{\infty} \phi_{m n} \cos \frac{m \pi x}{a} \sin \frac{n \pi y}{b} \\
& \psi(x, y)=\sum_{m=1}^{\infty} \sum_{n=1}^{\infty} \psi_{m n} \sin \frac{m \pi x}{a} \cos \frac{n \pi y}{b}
\end{aligned}
$$

where $w_{m n}, \phi_{m n}$, and $\psi_{m n}$ are coefficients, which can be easily evaluated after substitution of (13) in the set of three governing differential equations (6) and solving the resulting simultaneous equations. Having obtained the values of $w_{m n}, \phi_{m n}$, and $\psi_{m n}$ one can then calculate all the displacement and stress components within the plate.

\section{Displacement:}

Substituting the final solution for $w(x, y), \phi(x, y)$, and $\psi(x, y)$ in the displacement field, the final displacements can obtain.

The displacements are obtained as follows.

$$
\begin{aligned}
& u=\left[-z \bar{w}\left(\frac{m \pi}{a}\right)+f(z) \bar{\phi}\right] q_{m n} \cos \frac{m \pi x}{a} \sin \frac{n \pi y}{b} \\
& v=\left[-z \bar{w}\left(\frac{n \pi}{b}\right)+f(z) \bar{\psi}\right] q_{m n} \sin \frac{m \pi x}{a} \cos \frac{n \pi y}{b} \\
& w=\bar{w} q_{n n} \sin \frac{m \pi x}{a} \sin \frac{n \pi y}{b}
\end{aligned}
$$

\section{NumericAl RESUlts AND DisCUSSION}

Results obtained for displacements, stresses will now be compared and discussed with the corresponding results of Refined Plate Theory (RPT),Higher order shear deformation theory (HSDT) of Reddy, classical plate theory (CPT) of Kirchhoff, first order shear deformation theory (FSDT) of Reissner and an exact solution for analysis of plate Srinivas.

The transverse displacement, in-plane and transverse stresses are presented in the following non-dimensional form for the purpose of presenting the results in this paper

$$
\bar{w}=\frac{100 E w}{q h(A R)^{4}},\left(\bar{\sigma}_{x}, \bar{\sigma}_{y}, \bar{\tau}_{x y}\right)=\frac{\sigma_{x}, \sigma_{y}, \tau_{x y}}{q(A R)^{2}}, \quad\left(\bar{\tau}_{z x}, \bar{\tau}_{y z}\right)=\frac{\tau_{z x}, \tau_{y z}}{q(A R)}
$$

Further, it may be noted that $\tau_{z x}$ and $\bar{\tau}_{z x}$ obtained by constitutive relations are indicated by $\tau_{z x}{ }^{C R}$ and $\bar{\tau}_{z x}{ }^{C R}$ and they are indicated by $\tau_{z x}{ }^{E E}$ and $\bar{\tau}_{z x}{ }^{E E}$ when they are obtained by using equilibrium equations. Similar notations are also used for $\tau_{y z}$. The percentage error in result of a particular theory is shown in parenthesis in subsequent tables with respect to the result of exact elasticity solution which is calculated as follows

\section{$\%$ error $=\frac{\text { value by particular theory-value by exact elasticity solution }}{\text { value by exact elasticity solution }} \times 100$}

Results obtained for displacements and stresses are compared and discussed with the corresponding results of classical plate theory (CPT), first order shear deformation theory (FSDT), higher order shear deformation theories (HSDTs), of various authors and the exact elasticity solution of plate. For the purpose of comparison, results were specially generated according to the exact elasticity solution [26].

Example 1: Table 1 shows comparison of deflection and stresses for the simply supported homogenous rectangular isotropic plate subjected to uniformly distributed load for $a / b$ $=0.5, a / b=1.0$ and $h / a=0.1$. The present theory gives more accurate value of deflection than that is given by other refined theories as compared to exact value. The theory gives an exact value of in-plane normal stress $\bar{\sigma}_{x}$ and $\bar{\sigma}_{y}$ as compared to the value of exact solution for $a / b=1.0$ (refer figure 2 and 3 ). The value of in-plane shear stress obtained by present theory is in excellent agreement with the values of other refined theories. Transverse shear stress when obtained by constitutive relations using present theory is on higher side, however, use of equilibrium equations yield more accurate results in case of present theory as shown in figure 4 . 
Table2 shows comparison of non-dimensional natural bending mode frequencies of simply supported isotropic plate. It can be observed from Table 2 that the present theory yields excellent values of frequencies for almost all modes of vibration. The minimum $\%$ error predicted by present theory is $0.021 \%$.

\section{CONCLUSION}

In this paper Trigonometric Shear deformation Theory is presented for isotropic plate analysis. This theory gives realistic variation of transverse shear stress through the thickness of plate and satisfies the shear stress free boundary condition on the top and bottom planes of the plate. This theory obviates the shear correction factor. From the numerical results it is conclude that the values of transverse deflection, normal stress and shear stress obtained by this theory are in excellent agreement with those of the exact theory. Also it is notified that bending frequencies obtained by this theory are very close to the frequencies of exact theory and others theories.

\section{REFERENCES}

[1] S.P. Timoshenko and S.W. Krieger, "Theory of Plates and Shell," McGraw Hill, New York, 1959.

[2] E. Reissner and Y. Stavsky, "Bending and stretching of certain type of heterogeneous aelotropic elastic plates," Journal of Applied Mechanics, Vol. 28, Pp 402-408, 1961.

[3] G.R. Kirchhoff, "Uber das gleichgewicht und die bewegung einer elastischen Scheibe, Journal für die reine und angewandte Mathematik (Crelle's Journal)," Vol.40, Pp 51-88, 1850.

[4] S.G. Lekhnitskii, "Anisotropic plates," Gorden and Breach, New York, 1968.

[5] J. M. Whitney and A.W. Leissa, "Analysis of heterogeneous anisotropic plates,” Journal of Applied Mechanics, Vol. 36, Pp 261-266, 1969.

[6] R. Szilard, "Theory and analysis of plates-classical and numerical methods," Prentice-Hall Inc., Englewood Cliffs, New Jersey, 2004.

[7] J.M. Whitney and N.J. Pagano, "Shear Deformation in Heterogeneous Anisotropic plate," American Society of Mechanical Engineers. Journal Applied Mechanics, Vol. 37, Pp. 1031-1036, 1970.

[8] E. Reissner, "The Effect of transverse Shear Deformation on the Bending Elastic Plate," Transactions of the American society of Mechanical Engineers, Journal of Applied Mechanics, Vol. 12, Pp. 69$77,1945$.

[9] R.D. Mindlin, "Influence of Rotatory Inertia and Shear on Flexural Motions of Isotropic, Elastic Plates," ASME Journal of Applied Mechanics, Vol. 18, Pp.31-38, 1951.

[10] J.M. Whitney, "Shear Correction Factors for Orthotropic Laminates under Static Load," ASME Journal of Applied Mechanics, Vol.40, Pp.303-304. 1973.

[11] C.W. Bert, "A critical evaluation of new plate theories applied to laminated composites," Composite Structure., Vol.2, pp 329-347, 1984.

[12] A.K. Noor and W.S. Burton, "Assessment of SHEAR Deformation Theories for Multilayered Composite Plates," Applied Mechanics Reviews, Vol. 42, Pp.1-13, 1989.
[13] R. K. Kapania, and S. Reciti, "Recent advances in analysis of laminated Beams and Plates: Part-II," AIAA Journal., Vol.27, Pp 935-946, 1989.

[14] J.N. Reddy, "On the generalization of displacement-based laminate theories," Applied Mech. Rev., Vol. 42 S213-S222, 1989.

[15] Mallikarjuna and T. Kant, "A critical review and some results recently developed refine theories of fibre reinforced laminated composites and sandwiches," Composite Structures, Vol. 26, Pp. 293-312, 1993.

[16] J. N. Reddy and D. H. Robbins Jr., "Theories and computational Models for composite laminates," Applied Mech. Rev., 47, No 6, Pp 147-169, 1994.

[17] A.K. Noor, W.S. Burton and C.W. Bert, "Computational models for sandwich panels and shells," Applied Mech. Rev., Vol.49, Pp 155-199, 1996.

[18] K.H. Lo, R.M. Christensen, and E.M. Wu, "A High-Order Theory of Plate Deformation, Part-1: Homogeneous Plates," ASME Journal of Applied Mechanics, Vol. 44, Pp.663-668, 1977.

[19] K. H. Lo, R.M. Christensen and E.M. Wu, "A High-Order Theory of Plate Deformation, Part-2: Laminated Plates," ASME Journal of Applied Mechanics, Vol. 44, Pp.669-676, 1977.

[20] M. Stein, "Nonlinear Theory for Plates and Shells Including the Effects of Transverse Shearing," AIAA Journal, Vol. 24, Pp.1537-1544, 1986.

[21] M. Stein, D.C. Jegley, "Effect of Transverse Shearing on cylindrical bending, vibration buckling of laminated plates," AIAA Journal, Vol. 25, No. 1, Pp.123-129, 1997.

[22] J.N. Reddy, and N.D. Phan, "Stability and Vibration of isotropic, orthotropic and laminated plates according to higher order shear deformation theory," Journal of Sound and Vibration, Vol. 98, Pp. 157170, 1985.

[23] Y.M. Ghugal and A.S. Sayyad, "A static flexure of Thick Isotropic Plates Using Trigonometric Shear Deformation Theory,"Journal of Solid Mechanics, Vol.2, Pp.79-90, 2010.

[24] A.V. Krishna Murty, "Higher Order Theory for Vibrations of Thick Plates," AIAA Journal, Vol. 15, Pp.1823-1824, 1977.

[25] J.N. Reddy, "A simple Higher-order Theory for laminated Composites Plate," Transaction of the American Society of Mechanical Engineers, Journal Applied Mechanics, Vol. 51, Pp. 745-752, 1984.

[26] S. Srinivas, C.V. Joga Rao and A.K. Rao, "Bending, Vibration and buckling simply supported thick orthotropic rectangular plates and laminates," International Journal of Solids and Structures Pp. 6:1463$1481,1970$.

[27] R.M. Jones, "Mechanics of composite Material," McGraw Hill Kogakusha, Ltd., 1975.

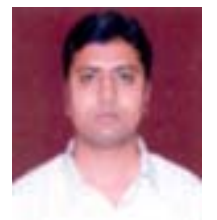

Imran I.Sayyad.

Aurangabad. D.O.B.-26/02/1980

B.E.(Mech.),M.B.A.,PGDFT.

E-mail-sayyadimrani@gmail.com 
Table1:

Comparison of deflection $\bar{w}$ at $(\mathrm{x}=\mathrm{a} / 2, \mathrm{y}=\mathrm{b} / 2, \mathrm{z}=0)$, in plane normal stresses $\overline{\sigma_{x}}$ at $(\mathrm{x}=\mathrm{a} / 2, \mathrm{y}=\mathrm{b} / 2, \mathrm{z}=\mathrm{h} / 2), \quad \overline{\sigma_{y}}$ at $(\mathrm{x}=\mathrm{a} / 2$, $\mathrm{y}=\mathrm{b} / 2, \mathrm{z}=\mathrm{h} / 2)$, in-plane shear stress $\overline{\tau_{x y}}(\mathrm{x}=0, \mathrm{y}=0, \mathrm{z}=\mathrm{h} / 2)$ and transverse shear stress $\overline{\tau_{z x}}$ at $(\mathrm{x}=0, \mathrm{y}=\mathrm{b} / 2, \mathrm{z}=0)$ in rectangular isotropic plate subjected to uniformly distributed load.

\begin{tabular}{|l|l|l|l|l|l|l|l|l|}
\hline$a / b$ & $h / a$ & Theory & $\bar{w}$ & $\overline{\sigma_{x}}$ & $\overline{\sigma_{y}}$ & $\overline{\tau_{x y}}$ & $\overline{\tau_{z x}}$ & $\overline{\tau_{z x}}$ \\
\hline 0.5 & 0.1 & Present & 11.415 & 0.613 & 0.279 & 0.325 & 0.705 & 0.6827 \\
\hline & & Ghugal and Sayyad[23] & 11.340 & 0.638 & 0.245 & 0.277 & 0.701 & 0.667 \\
\hline & & Krishnamurthy[24](HSDT) & 11.310 & 0.613 & 0.310 & 0.278 & 0.682 & 0.667 \\
\hline & & Reddy[25] (HSDT) & 11.420 & 0.612 & 0.278 & 0.280 & 0.679 & 0.6776 \\
\hline & & Mindlin[9] (FSDT) & 11.420 & 0.610 & 0.277 & 0.276 & 0.545 & 0.6865 \\
\hline & & Kirchoff [3] (CPT) & 11.060 & 0.610 & 0.278 & 0.277 & 0.686 & 0.6865 \\
\hline & & Exact[26] & 11.375 & 0.612 & 0.281 & ----- & 0.679 & ----- \\
\hline 1.0 & 0.1 & Present & 4.665 & 0.289 & 0.289 & 0.199 & 0.507 & 0.5003 \\
\hline & & Ghugal and Sayyad[23] & 4.625 & 0.307 & 0.307 & 0.195 & 0.504 & 0.481 \\
\hline & & Krishnamurthy[24](HSDT) & 4.639 & 0.290 & 0.290 & 0.195 & 0.490 & 0.480 \\
\hline & & Reddy[25] (HSDT) & 4.666 & 0.289 & 0.289 & 0.203 & 0.492 & 0.486 \\
\hline & & Mindlin[9] (FSDT) & 4.670 & 0.287 & 0.287 & 0.195 & 0.330 & 0.495 \\
\hline & & Kirchoff [3] (CPT) & 4.436 & 0.287 & 0.287 & 0.195 & ----- & 0.495 \\
\hline & & Exact[26] & 4.639 & 0.289 & 0.289 & ----- & 0.487 & ----- \\
\hline
\end{tabular}

Table 2: Comparison of natural frequencies of $\bar{\omega}_{m n}$ of simply supported isotropic square plate

\begin{tabular}{|l|c|c|c|c|c|c|c|}
\hline$(\mathrm{m}, \mathrm{n})$ & Exact[26] & Present & Mindlin[9] & Reddy[25] & Reissner $^{\mathrm{a}}$ & CPT[3] & $\begin{array}{c}\text { Ghugal and } \\
\text { Sayyyad[23] }\end{array}$ \\
\hline$(1,1)$ & 0.0932 & 0.09322 & 0.093 & 0.0931 & 0.093 & 0.0955 & 0.0933 \\
\hline$(1,2)$ & 0.2226 & 0.2224 & 0.2219 & 0.2222 & 0.2219 & 0.236 & 0.2231 \\
\hline$(2,2)$ & 0.3421 & 0.3404 & 0.3406 & 0.3411 & 0.3406 & 0.3732 & 0.3431 \\
\hline$(1,3)$ & 0.4171 & 0.4161 & 0.4149 & 0.4158 & 0.4149 & 0.4629 & 0.4184 \\
\hline$(2,3)$ & 0.5239 & 0.5229 & 0.5206 & 0.5221 & 0.5206 & 0.5951 & 0.5258 \\
\hline$(1,4)$ & $\ldots$ & 0.6533 & $\ldots \ldots$ & 0.6545 & 0.652 & 0.7668 & $\ldots \ldots .$. \\
\hline$(3,3)$ & 0.6889 & 0.6878 & 0.6834 & 0.6862 & 0.6834 & 0.809 & 0.6917 \\
\hline$(2,4)$ & 0.7511 & 0.7524 & 0.7446 & 0.7481 & 0.7446 & 0.8926 & 0.7542 \\
\hline$(3,4)$ & $\ldots$. & 0.8928 & $\ldots \ldots$ & 0.8949 & 0.8896 & 1.0965 & $\ldots \ldots .$. \\
\hline$(1,5)$ & 0.9268 & 0.923 & $\ldots \ldots$ & 0.923 & 0.9174 & 1.1365 & $\ldots \ldots .$. \\
\hline$(2,5)$ & $\ldots$ & 1.006 & $\ldots \ldots$ & 1.0053 & 0.9984 & 1.2549 & $\ldots \ldots .$. \\
\hline$(4,4)$ & 1.0889 & 1.078 & 1.0764 & 1.0847 & 1.0764 & 1.3716 & 1.0945 \\
\hline$(3,5)$ & $\ldots$. & 1.1328 & $\ldots \ldots$ & 1.1361 & 1.1268 & 1.4475 & $\ldots \ldots$. \\
\hline
\end{tabular}

$\bar{\omega}_{m n}=\omega_{m n} h \sqrt{\frac{\rho}{Q_{11}}} ; \mathrm{h} / \mathrm{a}=0.1 ; \mathrm{b} / \mathrm{a}=1.0 ; E_{2} / E_{1}=0.5250 ; G_{12} / E_{1}=0.26293 ; G_{13} / E_{1}=0.15991 ; G_{23} / E_{1}=0.26681 ; \mu_{12}=0.44046 ; \mu_{21}=0.23124$ 

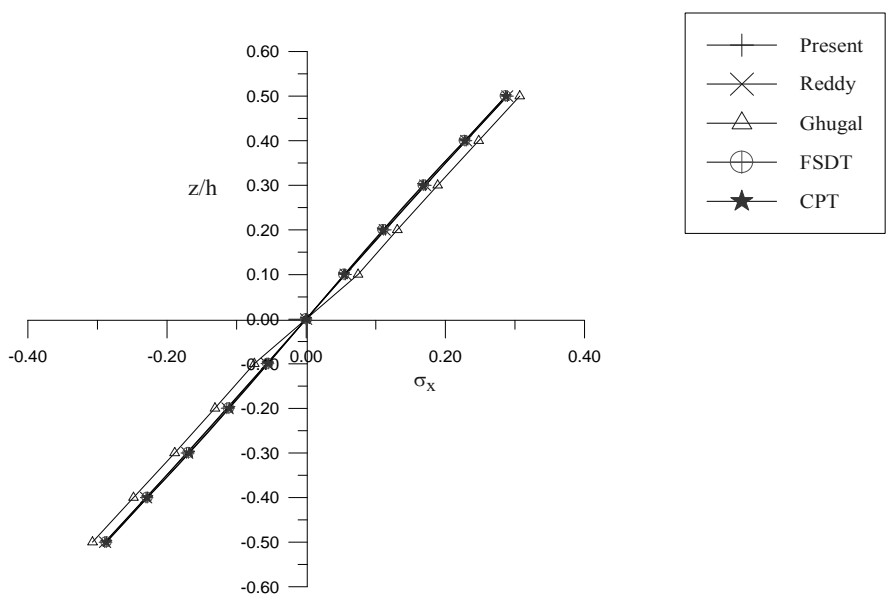

Figure 2: Comparison of in plane normal stresses $\bar{\sigma}_{x}$ at $(\mathrm{x}=\mathrm{a} / 2, \mathrm{y}=\mathrm{b} / 2, \mathrm{z}=\mathrm{h} / 2)$, in isotropic square plate subjected to uniformly distributed load(h/a=0.1).
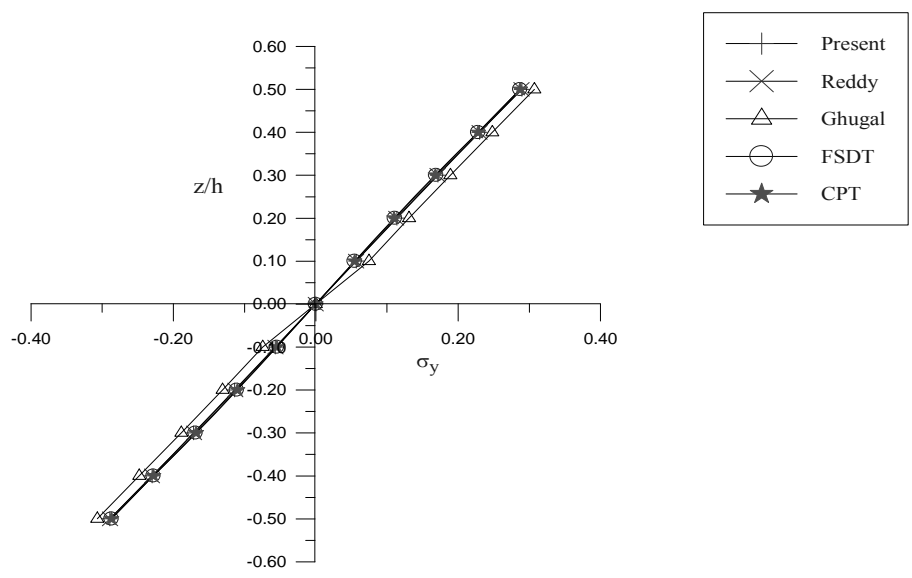

Figure 3: Comparison of in plane normal stresses $\overline{\sigma_{y}}$ at $(\mathrm{x}=\mathrm{a} / 2, \mathrm{y}=\mathrm{b} / 2, \mathrm{z}=\mathrm{h} / 2)$ in isotropic square plate subjected to uniformly distributed load $(\mathrm{h} / \mathrm{a}=0.1)$.

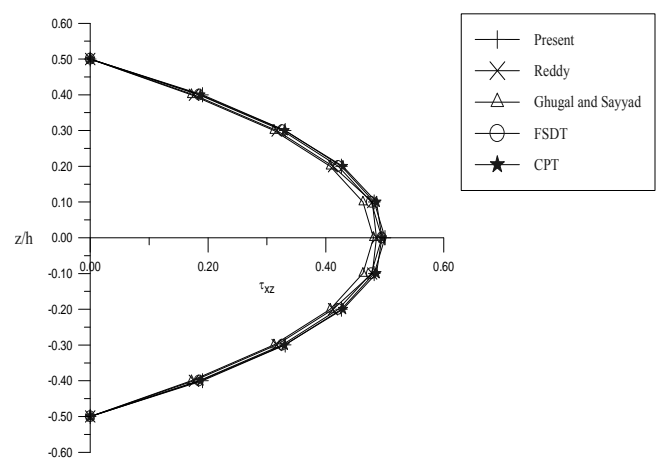

Figure 4: Comparison of transverse shear stress $\overline{\tau_{z x}}$ at $(\mathrm{x}=0, \mathrm{y}=\mathrm{b} / 2, \mathrm{z}=0)$ in isotropic square plate subjected to uniformly distributed load(h/a=0.1). 